\title{
Nonlinear interactive analysis of cooling tower-foundation-soil interaction under unsymmetrical wind load
}

\begin{abstract}
This paper deals with physical and material modelling of a cooling tower-foundation-soil system. The physical modelling has been carried out using solid 20-noded isoparametric element to model the cooling tower, annular raft foundation and soil media. The cooling tower-foundation-soil system was analysed under vertical and lateral load generated due to self-weight and wind loads. The soil nonlinearity has been taken into consideration using hyperbolic nonlinear elastic constitutive law. The response of the structure has been investigated with respect to displacement and stresses. Moreover, an attempt has been made to study the effect of the linear and nonlinear interactive analyses compared with conventional analysis. It was seen that the interactive analysis of the cooling towerfoundation-soil media plays a major role in releasing the stresses in the cooling tower, particularly at the bottom ring beam.
\end{abstract}

Keyword: Cooling tower, Wind load, Soil-structure interaction, Linear analysis, Nonlinear analysis 